\title{
Pharmacologic Management of Perioperative Pulmonary Hypertension
}

\author{
Julie W. Cheng, MAE,* Adriano R. Tonelli, MD, $\dagger$ Gosta Pettersson, MD, PhD, $\neq$ \\ and Richard A. Krasuski, MD, FACC§
}

\begin{abstract}
Perioperative pulmonary hypertension can originate from an established disease or acutely develop within the surgical setting. Patients with increased pulmonary vascular resistance are consequently at greater risk for complications. Despite the various specific therapies available, the ideal therapeutic approach in this patient population is not currently clear. This article describes the basic principles of perioperative pulmonary hypertension and reviews the different classes of agents used to promote pulmonary vasodilation in the surgical setting.
\end{abstract}

Key Words: pulmonary hypertension, perioperative care, pulmonary vasodilators

(J Cardiovasc Pharmacol ${ }^{\mathrm{TM}}$ 2014;63:375-384)

\section{INTRODUCTION}

Patients with pulmonary hypertension $(\mathrm{PH})$ experience increased morbidity and mortality after cardiac, noncardiac, and transplant surgeries. Patients more frequently experience complications, such as acute right heart failure, delayed extubation, and early postoperative death. ${ }^{1-7}$ Despite important therapeutic advances in the management of $\mathrm{PH}$, there is still a marked delay between the start of $\mathrm{PH}$ symptoms and the diagnosis of the disease by right heart catheterization. A multicenter registry demonstrated a delay in disease diagnosis of $2.8 \pm 5$ years. ${ }^{8}$ This suggests that $\mathrm{PH}$ may remain undiagnosed or underestimated at the time of surgery, and as a result, these patients would be at risk for developing associated complications before proper evaluation or intervention. Although studies have evaluated the efficacy of various forms of therapy within the surgical setting, guidelines for perioperative management in the adult population are limited and

Received for publication August 2, 2013; accepted November 13, 2013.

From the *Case Western Reserve University School of Medicine, Cleveland, $\mathrm{OH}$; Departments of $\uparrow$ Pulmonary, Allergy, and Critical Care Medicine; and $\ddagger$ Thoracic and Cardiovascular Surgery, Cleveland Clinic, Cleveland, $\mathrm{OH}$; and §Department of Cardiovascular Medicine, Heart and Vascular Institute, Cleveland Clinic, Cleveland, $\mathrm{OH}$.

A.R.T. is supported by the CTSA KL2 Grant \# RR024990, from the National Center for Research Resources (NCRR), a component of the National Institutes of Health (NIH), and NIH Roadmap for Medical Research. R.A.K. is a consultant and on the speaker's bureau of Actelion Pharmaceuticals and on the scientific advisory board for Ventripoint.

The authors report no conflicts of interest.

Reprints: Richard A. Krasuski, MD, FACC, Department of Cardiovascular Medicine, Heart and Vascular Institute, Cleveland Clinic, 9500 Euclid Avenue/Mail Code J2-4, Cleveland, OH 44195 (e-mail: krasusr@ccf.org). Copyright $(\underset{C}{2013}$ by Lippincott Williams \& Wilkins unclear. The purpose of this review is to discuss the principles of management, focusing on the currently available pharmacologic options.

\section{PERIOPERATIVE PULMONARY HYPERTENSION}

Perioperative $\mathrm{PH}$ can be attributed to an established disease or acute development within the operative setting. Because patients present with nonspecific clinical manifestations, such as dyspnea or fatigue, $\mathrm{PH}$ is diagnosed based on hemodynamic criteria through a pulmonary arterial pressure (PAP) of $\geq 25 \mathrm{~mm} \mathrm{Hg}$ at rest. Echocardiography provides a noninvasive means of estimating PAP and assessing right ventricular (RV) function. Right heart catheterization, however, provides accurate measurement of PAP in addition to other pulmonary hemodynamic parameters. Measurements of pulmonary artery occlusion pressure, cardiac index, and pulmonary vascular resistance (PVR) can aid in distinguishing the etiology of $\mathrm{PH}$ and provide a more accurate assessment of disease severity.

Pre-existing $\mathrm{PH}$ can be idiopathic or arise secondary to underlying cardiac or pulmonary diseases (Table 1). ${ }^{9}$ Because chronic PH can result from multiple etiologic mechanisms, the pathogenesis of each condition can vary and ultimately determine the preoperative assessment, operative course, and clinical outcomes of these patients. Patients with previously diagnosed PH who undergo surgery should be evaluated preoperatively for PH severity and comorbid conditions. In addition to baseline hemodynamic parameters, patients should also be assessed by their response to inhaled pulmonary vasodilators. This can provide a predictive measure of a patient's potential to respond to perioperative management with pulmonary vasodilators. Despite the risk for complications, patients with these conditions often undergo surgical procedures and subsequently require management for perioperative $\mathrm{PH}$. In addition to the clinical condition of the patient, multiple factors can influence the development and progression of $\mathrm{PH}$ within the operative setting.

Perioperative PH can develop acutely as a result of iatrogenic interventions or operative events that lead to pulmonary vasoconstriction (Table 2). As a result, an increase in PAP is required to overcome this resistance to maintain blood flow within the pulmonary vasculature. This increase in afterload, however, can ultimately lead to potentially fatal complications, such as pulmonary hypertensive crisis (defined as a PAP equal to or greater than systemic arterial pressure) or RV dysfunction (Fig. 1). 
TABLE 1. Updated Classification of Pulmonary Hypertension by the World Health Organization ${ }^{9}$

\begin{tabular}{|c|c|c|}
\hline Group & Description & Examples \\
\hline Group 1 & Pulmonary arterial hypertension & $\begin{array}{l}\text { Primary } \\
\text { - Idiopathic } \\
\text { - Heritable: BMPR2, ALK1/endoglin, unknown } \\
\text { Secondary } \\
\text { - Connective tissue disease } \\
\text { - Congenital disease (left-to-right shunt) } \\
\text { - Portal hypertension } \\
\text { - Infection: HIV or shistosomiasis } \\
\text { - Chronic hemolytic anemia } \\
\text { - Persistent pulmonary hypertension of the newborn }\end{array}$ \\
\hline Group $1^{\prime}$ & & $\begin{array}{l}\text { Drugs and toxins } \\
\text { Pulmonary vaso-occlusive disease } \\
\text { Pulmonary capillary hemangiomatosis }\end{array}$ \\
\hline Group 3 & $\begin{array}{l}\text { Pulmonary hypertension associated with lung disease or } \\
\text { hypoxemia }\end{array}$ & $\begin{array}{l}\text { Chronic obstructive pulmonary disease } \\
\text { Interstitial lung disease } \\
\text { Sleep-disordered breathing } \\
\text { Alveolar hypoventilation disorders } \\
\text { Chronic high altitude } \\
\text { Developmental abnormalities }\end{array}$ \\
\hline Group 4 & Pulmonary hypertension secondary to chronic obstruction & $\begin{array}{l}\text { Thromboembolic obstruction of proximal pulmonary arteries } \\
\text { Thromboembolic obstruction of distal pulmonary arteries } \\
\text { Nonthrombotic obstruction: tumor, parasites, foreign material }\end{array}$ \\
\hline Group 5 & $\begin{array}{l}\text { Pulmonary hypertension due to unclear multifactorial } \\
\text { mechanisms }\end{array}$ & $\begin{array}{l}\text { - Hematologic: myeloproliferative disorders, splenectomy, myoglobinopathy } \\
\text { - Systemic: sarcoidosis, pulmonary Langerhans cell } \\
\text { - Metabolic: glycogen storage disease, Gaucher disease, thyroid disorder } \\
\text { - Other: tumor obstruction, fibrosing mediastinitis, chronic renal failure on } \\
\text { dialysis }\end{array}$ \\
\hline
\end{tabular}

Because cardiogenic shock secondary to RV failure can result in mortality rates of approximately 53\% that are comparable to those of LV failure ${ }^{10}$ this is a primary concern of perioperative $\mathrm{PH}$ management.

Iatrogenic interventions, including cardiopulmonary bypass (CPB) or mechanical ventilation, have resulted in a perioperative increase in resistance and pressure within the pulmonary vessels. Both cardiac and noncardiac thoracic surgery have been associated with perioperative $\mathrm{PH}$, as these procedures may require $\mathrm{CPB}$ to temporarily replace heart and lung function. However, exposure to $\mathrm{CPB}$ has been shown to result in myocardial and pulmonary injury, significantly increased PVR and decreased pulmonary compliance. ${ }^{11,12}$ Mechanical ventilation can acutely increase PVR by overdistending alveoli or increasing the risk for developing respiratory acid-base disturbances. Increased $\mathrm{PaCO}_{2}$ levels and acidotic conditions directly increase in PAP and PVR within the operative setting. ${ }^{13-15}$ As a slight hypocarbic alkalosis seems to be beneficial in minimizing resistance, ${ }^{15}$ blood gas levels should be closely monitored.

General surgical complications can also increase afterload. In addition to contributing to the chronic form of this condition, ${ }^{9}$ pulmonary emboli have been associated with acute development of $\mathrm{PH}^{4}{ }^{4}$ Obstruction secondary to a thrombotic event reduces the cross-sectional area of pulmonary vasculature and results in an increase in pressure. Furthermore, wound infections and anemia secondary to blood loss contribute to perioperative $\mathrm{PH}$ through altered acid-base balance and limited oxygen delivery, respectively. RV afterload should therefore be minimized through the immediate recognition and treatment of these complications.

Although it does not directly impact pulmonary vasculature, altered RV preload can affect RV function through a loss of fluid balance. Neurohormonal imbalance, underlying conditions, or exogenously administered fluids can lead to fluid overload. Not only could this exacerbate RV 
TABLE 2. Factors Leading to an Acute Increase in PVR and Risk of RV Dysfunction

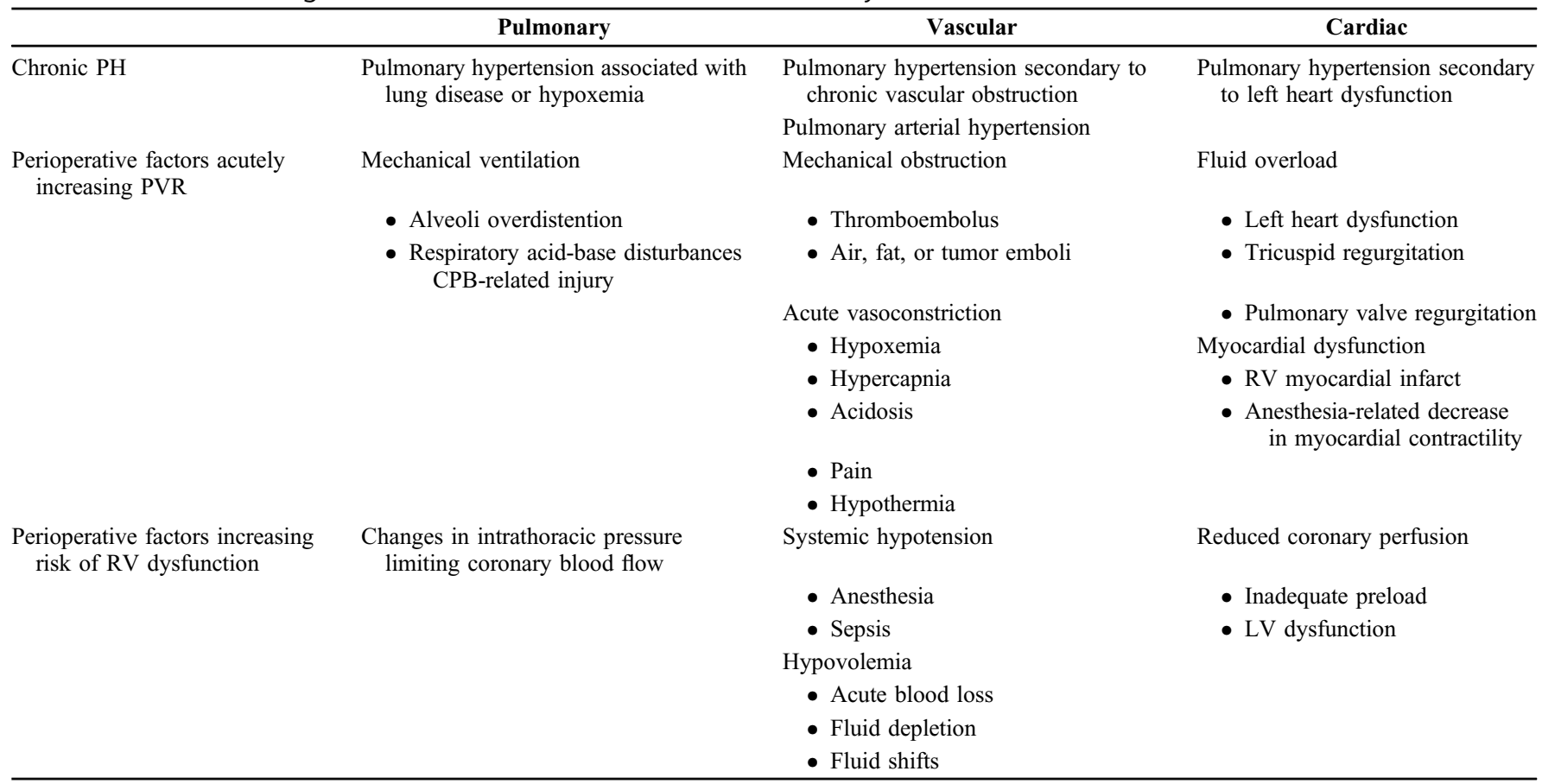

dysfunction, but it may also compromise LV filling and cardiac output through interventricular dependence. However, volume depletion from blood loss, fluid shifts, or excessive diuresis can decrease the LV preload and cardiac output.
Subsequent hypotension and limited systemic perfusion may decrease coronary perfusion and place the heart as risk for ischemia. Within the context of chronic $\mathrm{PH}$, the $\mathrm{RV}$ has undergone structural remodeling that predisposes it to an
FIGURE 1. Operative factors affecting pulmonary hypertension and associated RV failure.

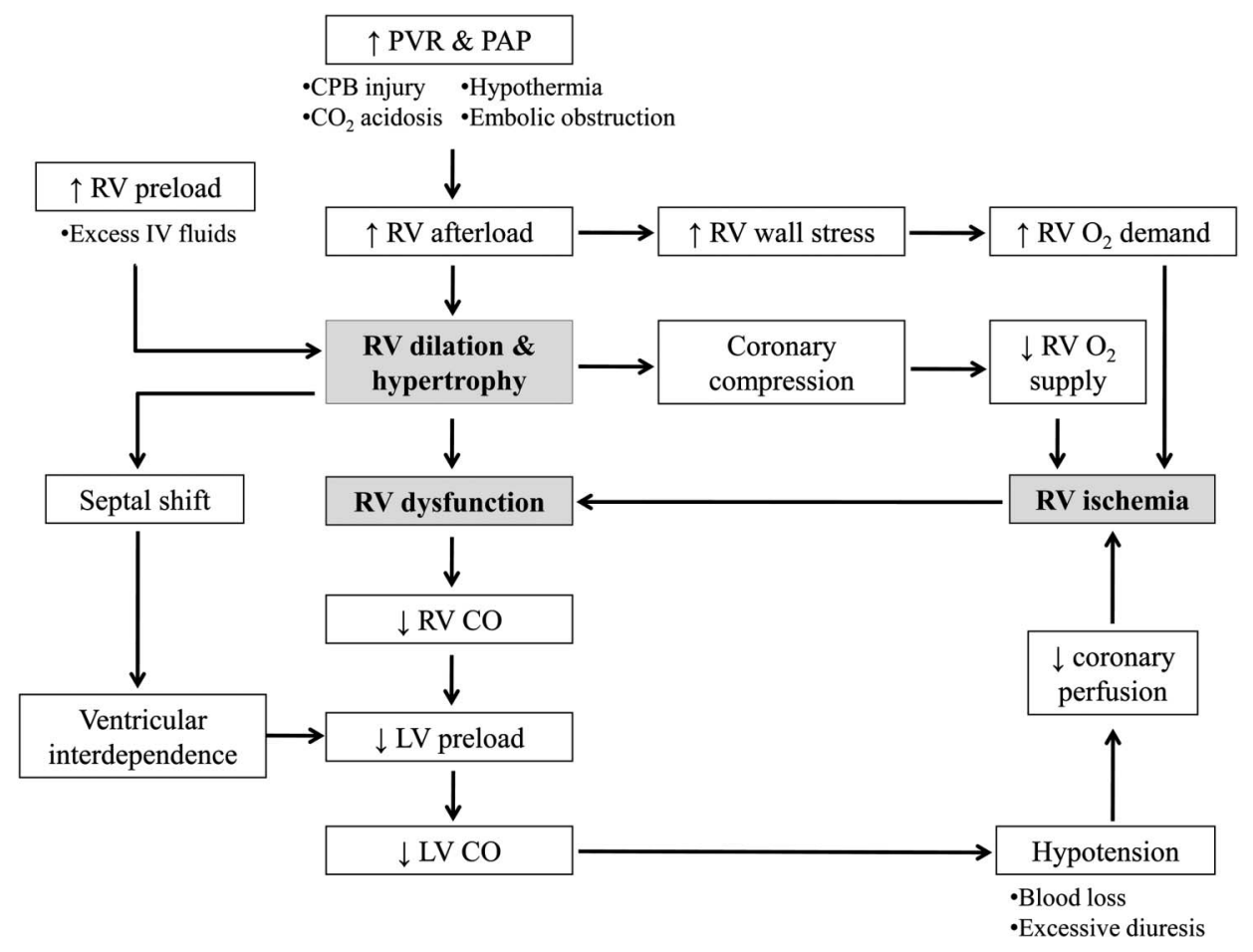


imbalance between oxygen supply and demand. ${ }^{16}$ Increased wall stress and coronary compression results in an increase in oxygen consumption and limited oxygen delivery. ${ }^{16}$ In addition to maintaining proper fluid balance, blood pressure should be carefully monitored and appropriate diuretics or vasopressors should be administered as necessary.

Pulmonary hypertension may be suspected within the operative or perioperative setting by signs of systemic congestion suggestive of acute right heart dysfunction or evidence of RV strain and structural change, such as tricuspid regurgitation or right axis deviation and bundle branch block on electrocardiogram. Prompt recognition and diagnosis through echocardiography or right heart catheterization can help optimize management.

\section{PULMONARY VASODILATORS}

Pulmonary hypertension can be managed directly by the judicious use of pulmonary vasodilator therapy within the perioperative setting (Table 3). Endothelial injury and dysfunction cause an imbalance between vasodilators and vasoconstrictors that ultimately results in increased PVR. Decreased production of endogenous pulmonary vasodilators results in the loss of vascular compliance, platelet aggregation inhibition, and dysregulation of smooth muscle proliferation. The goal of perioperative PH therapy is to maximize pulmonary vasodilation and reduce PVR. This decrease in RV afterload subsequently improves cardiac output. However, agents that cause pulmonary vasodilation can also decrease systemic vascular resistance (SVR) and mean arterial pressure (MAP). As discussed above, this would decrease systemic perfusion and increase the risk of cardiac ischemia.

Because treatment for $\mathrm{PH}$ is limited by untoward reduction in SVR, inhaled pulmonary vasodilators have become the preferred method of management over their oral and intravenous counterparts. Inhaled agents, such as nitric oxide (NO) and nebulized iloprost, are inactivated before reaching systemic circulation and therefore have lesser impact on systemic hemodynamics. Furthermore, by reaching wellventilated regions of the lung, these agents may improve ventilation-perfusion matching and subsequently improve oxygenation. Although inhaled agents demonstrate greater pulmonary specificity than those with systemic administration, the risk of causing systemic hypotension, although lower, nevertheless remains. A disadvantage of continuous nebulization is that only an indeterminate proportion of aerosolized medication actually reaches the alveoli and pulmonary vessels during the inspiratory phase. Regardless of the dosage, this ultimately results in an imprecise delivery of medication that makes it difficult to monitor.

Treatment should ideally be tailored to the etiology of PH and the clinical condition of the patient. There are instances in which pulmonary vasodilators can exacerbate clinical conditions. As pulmonary vasodilation increases blood flow through arteriolar and capillary circulation, an increase in pulmonary venous pressure can worsen left heart congestion and result in pulmonary edema in patients with left heart failure and other forms of pulmonary

TABLE 3. Summary Table of Pulmonary Vasodilators Used Within the Perioperative Setting

\begin{tabular}{|c|c|c|}
\hline & Advantages & Disadvantages \\
\hline Inhaled NO & Selective pulmonary vasodilation & $\begin{array}{l}\text { Specialized equipment required } \\
\text { Short duration of action } \\
\text { Toxic metabolites } \\
\text { Potential contribution to pathogenesis of sepsis } \\
\text { Rebound PH on withdrawal }\end{array}$ \\
\hline NO donors & $\begin{array}{l}\text { Induce venodilation to enable management of } \mathrm{PH} \\
\text { secondary to left heart disease }\end{array}$ & \\
\hline $\begin{array}{l}\text { - Nitroglycerin } \\
\text { Prostacyclin and analogs }\end{array}$ & Selective pulmonary vasodilation (nebulized form) & Reduction in cardiac output \\
\hline - Inhaled prostacyclin & Minimal systemic effects (even at high doses) & $\begin{array}{l}\text { Short duration of action } \\
\text { Rebound } \mathrm{PH} \text { on withdrawal } \\
\text { Platelet aggregation inhibited in vitro }\end{array}$ \\
\hline PDE inhibitors & & \\
\hline - Milrinone & Decrease in pulmonary capillary wedge pressure & $\begin{array}{l}\text { Systemic hypotension (reported with intravenous } \\
\text { administration) }\end{array}$ \\
\hline - Sildenafil & $\begin{array}{l}\text { Selective pulmonary vasodilation } \\
\text { Limit effects of NO withdrawal } \\
\text { Easy to administer (oral or intravenous) } \\
\text { Combination therapy }\end{array}$ & $\begin{array}{l}\text { Reported cases of systemic hypotension } \\
\text { May worsen oxygenation status }\end{array}$ \\
\hline
\end{tabular}


veno-occlusive disease. These patients may subsequently require treatment with agents that promote venodilation, such as sodium nitroprusside (SNP) or nitroglycerin. Furthermore, increasing blood flow to poorly ventilated regions can result in ventilation-perfusion mismatch and worsen hypoxemia in patients with parenchymal lung disease.

When individual agents are ineffective, combination therapy provides an additional option for managing perioperative PH. This can augment the effect of individual pulmonary vasodilator agents, particularly when there are different mechanisms of action involved. For example, the effects of a pharmacologic NO donor, such as SNP, can be augmented when administered with a phosphodiesterase-5 inhibitor that suppresses NO metabolism, such as sildenafil. The integration of separate mechanisms of action, however, must be used carefully as an inappropriate combination of pulmonary vasodilators may produce or aggravate systemic hypotension. For example, the contraindicated use of nitroglycerin and phosphodiesterase-5 inhibitors, such as sildenafil, should be considered when determining appropriate agents. Furthermore, combination therapy can be complicated with regard to the method and timing of drug administration, which is already challenging with a single agent alone.

\section{Inhaled NO}

NO produced endogenously by the vascular endothelium increases cyclic guanosine monophosphate (cGMP) production, which promotes relaxation of vascular tone and reduces smooth muscle proliferation. Endothelial dysfunction results in diminished NO production and contributes to the pathophysiology of PH. Inhaled NO targets this deficiency. The short half-life of this agent necessitates continuous administration using specialized equipment.

The Food and Drug Administration has approved this agent for the management of $\mathrm{PH}$ in the pediatric population. NO has also been used for preventative PH management and rescue therapy from pulmonary hypertensive crisis. Because it is inactivated quickly by hemoglobin, NO has limited systemic effects and more specific action on the pulmonary vasculature. As a result, there is an improvement in pulmonary hemodynamics without systemic side effects, such as reduced SVR or diminished cardiac output. ${ }^{17}$

NO has been demonstrated to be effective postoperatively in children undergoing congenital heart surgery. Patients with preoperative $\mathrm{PH}$ exhibited significant decreases in mean PAP and PVR compared with control groups undergoing hyperventilation ${ }^{17}$ or receiving placebo nitrogen gas. ${ }^{18,19}$ Incidence of pulmonary hypertensive crisis, time to extubation, and length of postoperative course were also significantly reduced when using $\mathrm{NO}$ to manage postoperative PH. ${ }^{19}$ Inhaled NO has also been effective for treatment in the adult population. ${ }^{20-23}$ Inhaled NO significantly reduced PAP and increased cardiac index and systemic blood pressure in high-risk cardiac surgery patients. ${ }^{20-22}$ It was also effective in improving RV ejection fraction and reducing the need for vasopressor treatment. ${ }^{22,23}$

Despite reducing PAP and PVR in patients who developed perioperative $\mathrm{PH}$, NO did not decrease intensive care stay or reduce mortality compared with inhalation of placebo gas. ${ }^{19}$ A separate study found that NO induced similar hemodynamic changes and did not significantly decrease the incidence of pulmonary hypertensive crisis compared with other forms of conventional treatment selected by the treating physicians. $^{24}$

A concern with NO inhalation is the formation of toxic metabolites, including methemoglobin, nitrogen dioxide, and peroxynitrite free radicals. ${ }^{25}$ These compounds cause tissue hypoxia or directly damage the respiratory tract. ${ }^{25} \mathrm{NO}$ administered with a high fraction of inspired oxygen can lead to free radical formation and subsequent peroxynitrite-mediated oxidative cell death. ${ }^{26}$ It has also been shown to damage surfactant apoproteins and limit the ability of pulmonary surfactant to reduce alveolar surface tension. ${ }^{27}$

It should be noted that modifying the NO pathway could also complicate the management of patients with impending or established sepsis. Increased levels of NO have been demonstrated in patients with sepsis and hypothesized to contribute to its pathogenesis. ${ }^{28-30}$ There is also an increased cardiac demand during infection that may not be met by the limited RV contractile reserve of patients with $\mathrm{PH}$. As a result, the potential systemic effects of inhaled NO, though minimal, may compound the systemic effects (hypotension) and associated complications of sepsis.

NO poses additional complications during withdrawal, when patients can experience rebound $\mathrm{PH}$ with life-threatening increases in PAP and decreases in oxygenation. ${ }^{31,32}$ Various mechanisms have been proposed to contribute to rebound $\mathrm{PH}$. These include transient decreases in endogenous NO synthase activity, guanylate cyclase levels, and cGMP concentrations $^{33,34}$ with maintained activity of phosphodiesterases in plasma and lung tissue. ${ }^{34}$ Both these processes would be expected to lead to NO deficiency and lessened intrinsic ability to dilate the pulmonary vasculature.

NO may also transiently increase endothelin-1 (ET-1) levels, which can stimulate vasoconstriction. In one study examining patients undergoing congenital heart disease repair, plasma ET-1 levels significantly increased during NO administration and remained elevated until therapy was discontinued, although levels decreased in controls not receiving postoperative NO. ${ }^{35}$ The same authors found similar ET-1 elevations in patients receiving NO for acute respiratory distress syndrome. ${ }^{35}$

Because patients successfully weaned from NO experience lower postoperative morbidity, ${ }^{36}$ factors influencing NO withdrawal have been carefully scrutinized. Successful discontinuation is associated with longer duration of inhalation and lower dose at discontinuation. ${ }^{36}$ Complications associated with NO withdrawal may be managed through the use of sildenafil. ${ }^{37,38}$ Through phosphodiesterase-5 inhibition, sildenafil maintains cGMP availability. In one study, there was no incidence of rebound $\mathrm{PH}$ in children after a single dose of sildenafil 1 hour before planned NO withdrawal. ${ }^{37}$ These patients also required a shorter duration of mechanical ventilation compared with those receiving placebo interventions. In addition to preventing rebound $\mathrm{PH}$, sildenafil was also beneficial for patients who had already failed NO weaning by enabling subsequent weans to occur without increased PAP or altered systemic pressure. ${ }^{38}$ 
An additional drawback of NO is its increased cost in relation to other commonly utilized agents. Although this is not a sole factor in determining an appropriate therapeutic agent, rebound $\mathrm{PH}$ after withdrawal and its toxic metabolites may not justify the routine use of NO. Alternatives to NO do not require special equipment and can be administered through infusion and continuous nebulization. These agents have been compared with NO with regard to efficacy and tolerability and are described below.

\section{NO Donors}

SNP and nitroglycerin are classified as NO donors that induce enzymatic release of this vasodilator. Because they preferentially induce venodilation, these agents are most commonly used to treat $\mathrm{PH}$ resulting from chronic pulmonary venous obstruction, such as in left heart and valve dysfunction. The pulmonary vascular bed can be specifically targeted by these drugs through aerosolized administration.

SNP increases cGMP levels by promoting direct NO release from the vascular endothelium. As SNP promotes arterial vasodilation in addition to venodilation, this agent can also reduce afterload and improve cardiac output. Although treatment with intravenous SNP results in severe systemic hypotension in patients undergoing mitral valve replacement, ${ }^{21}$ the inhaled version of this drug has been found to promote local NO release at pulmonary vasculature. ${ }^{39}$ Nebulized SNP was effective in selectively decreasing PAP and PVR in animal models of PH. ${ }^{39-41}$ Although PVR was selectively reduced without systemic effects at lower doses, higher doses of inhaled SNP did result in systemic hypotension. ${ }^{42}$ Unfortunately, no recommended dosing for adults has been published. Although clinical studies of inhaled SNP are currently limited, this agent nevertheless exhibits dose-dependent pulmonary specificity that may vary with the underlying etiology of $\mathrm{PH}^{41}$

Nitroglycerin also increases levels of NO to induce vasodilation. Nitroglycerin acts as a prodrug that is metabolized to NO and preferentially exerts its actions on the venous circulation. By decreasing ventricular preload, this agent reduces right-sided cardiac output and relieves the pulmonary congestion that results from left heart dysfunction. This agent has also been found to induce selective pulmonary vasodilation when administered in aerosolized form. ${ }^{43,44}$ Inhaled nitroglycerin significantly reduced mean PAP without significant changes in systemic resistance or cardiac index in children with congenital heart disease $\mathrm{e}^{45,46}$ and adults undergoing mitral valve surgery. ${ }^{44,47,48}$ Although neither SNP or nitroglycerin are as commonly used as NO, inhaled versions of these drugs nevertheless demonstrate pulmonary specificity and offer attractive alternative options for $\mathrm{PH}$ management.

\section{Prostacyclin and Prostacyclin Analogues}

Prostacyclin is produced by prostacyclin synthase via the arachidonic pathway at the vascular endothelium. By activating adenylate cyclase and increasing cAMP production, prostacyclin inhibits platelet aggregation and promotes smooth muscle relaxation to lower PAP. Patients with $\mathrm{PH}$ exhibit a loss of prostacyclin synthase that results in decreased prostacyclin production. Similar to NO, prostacyclin and prostacyclin analogues (epoprostenol, iloprost and treprostinil) have been administered exogenously to treat $\mathrm{PH}$. The pulmonary specificity of these agents varies by the method of administration. Intravenous prostacyclin was shown to decrease SVR in patients undergoing orthotopic heart transplantation but can result in severe hypotension. ${ }^{49}$ In contrast, inhaled prostacyclin and prostacyclin analogues exhibit pulmonary specificity and inhalation has subsequently become the preferred method of perioperative administration.

\section{Inhaled Prostacyclin}

Limited studies have shown that inhalational prostacyclin is safe and effective in treating acute intraoperative $\mathrm{PH}$ and RV failure. ${ }^{50,51}$ It significantly reduced PAP and PVR and improved RV performance with minimal systemic effects in patients undergoing cardiothoracic surgery or heart transplantation. $^{21,50-53}$ This agent has also been effective in treating perioperative portopulmonary hypertension secondary to liver failure. ${ }^{54}$ Unlike SNP, increased administration consistently results in dose-dependent pulmonary vasodilation without any significant impact on systemic resistance. ${ }^{51}$ Despite the expectation of selected pulmonary delivery, hypotension with inhaled prostacyclin administration has been reported, suggesting systemic provision. ${ }^{55}$ As the hypotension was limited mainly to patients with systemic hypotension before surgery, confounding factors cannot be excluded as the cause.

Comparison studies have shown that inhaled prostacyclin seems as effective as NO in reducing PAP and improving cardiac index and mixed venous oxygen saturation. ${ }^{21,56}$ Heart and lung transplant recipients receiving inhaled NO or inhaled prostacyclin demonstrated similar degrees of PAP reduction and cardiac output increase. ${ }^{56}$ Furthermore, oxygenation index and systemic blood pressure were unaffected by both agents. ${ }^{56}$ Another study demonstrated that inhaled prostacyclin may actually be more effective than NO in acutely managing primary and secondary $\mathrm{PH}$. Nebulized prostacyclin resulted in significantly greater reduction in mean PAP than inhaled NO without any significant change in systemic pressure. $^{57}$

Additional studies will be required comparing the efficacy and complications of inhaled NO and prostacyclin before the latter can be considered an adequate alternative for managing perioperative $\mathrm{PH}$. Compared with NO, however, inhaled prostacyclin seems to be significantly more costeffective. Furthermore, prostacyclin does not produce the toxic metabolites or exhibit the same rate of potential complications as NO. Although prostacyclin inhibits platelet aggregation in vitro, this has not to date demonstrated a prolongation in bleeding time or increase in chest tube drainage when utilized in cardiac surgery. ${ }^{53,58}$ Rebound $\mathrm{PH}$ after prostacyclin use has, however, been reported in a highrisk patient who experienced increased RV afterload and developed cardiogenic shock after its withdrawal. ${ }^{59}$ Because NO and prostacyclin exhibit half-lives lasting seconds to minutes, withdrawal of either agent can cause an acute loss of vasodilation that results in rebound $\mathrm{PH}^{59}$

\section{Inhaled Iloprost}

Iloprost is a prostacyclin analogue that offers a more stable molecule with a longer duration of action. This agent has 
also been shown to significantly decrease PAP and PVR and improve cardiac index when administered after cardiac surgery ${ }^{48,60,61}$ or heart transplantation. ${ }^{62}$ Iloprost was also effective in optimizing pulmonary hemodynamics in patients undergoing pulmonary thromboendarterectomy for chronic thromboembolic $\mathrm{PH}^{63}$ In addition to preventing acute RV failure, ${ }^{60}$ iloprost therapy improved indices of RV function as measured by echocardiography. ${ }^{61}$ This agent also significantly decreased pulmonary pressures and improved oxygen saturation when it was used as rescue therapy for pulmonary hypertensive crises after congenital heart surgery. ${ }^{64}$ Additionally, there were no significant changes in MAP, SVR, bleeding complications, or incidence of bronchospasm after treatment. ${ }^{62-65}$ Because iloprost is not as rapidly inactivated as NO or inhaled prostacyclin, there have been no reports of rebound $\mathrm{PH}^{66}$

Although iloprost is as effective as inhaled NO in preventing pulmonary hypertensive crises ${ }^{67}$ studies have shown that iloprost may be more effective than $\mathrm{NO}$ when used for management of $\mathrm{PH}^{66,68,69}$ Within the nonsurgical context of pulmonary arterial hypertension, $\mathrm{NO}$ and iloprost led to significant increases in cardiac output and mixedvenous oxygen saturation, as well as significant reductions in PAP and PVR. ${ }^{66}$ However, patients treated with iloprost exhibited more pronounced hemodynamic changes in each parameter. ${ }^{66}$ Inhaled iloprost also induces greater levels of pulmonary vasodilation than NO within the perioperative setting. ${ }^{68,69}$ Cardiac surgery patients treated with iloprost exhibited greater improvements in cardiac output in addition to better PAP and PVR reduction when weaned from CPB. ${ }^{68}$ Heart transplant patients treated with iloprost demonstrated a more reliable reduction in PAP and improvement in cardiac index compared with a small proportion of patients who actually experienced an increase in PVR with NO administration. ${ }^{69}$

Iloprost also exhibited a protective effect against ischemia-reperfusion injury in an animal model. ${ }^{70}$ Treatment with iloprost before mechanical injury completely prevented pulmonary edema, maintained vasoconstrictor ET-1 balance, and significantly decreased PVR. ${ }^{70}$ Although further studies are needed, these data suggest that iloprost may find a role in preventing the development or worsening of perioperative $\mathrm{PH}$ by reducing injury from surgical vascular manipulation.

\section{Phosphodiesterase Inhibitors}

Phosphodiesterase inhibitors slow metabolism of the second messengers cAMP and cGMP to promote acute vasodilation. By maintaining these substrates, phosphodiesterase inhibitors ultimately potentiate the effects of prostacyclins and NO.

\section{Milrinone}

Milrinone is a type 3 phosphodiesterase inhibitor that maintains cAMP concentrations in myocardial and smooth muscle cells. As a result, milrinone promotes cardiac contractility and vasodilation at the pulmonary vasculature. A comparison between intravenous milrinone and inhaled NO revealed that milrinone required greater vasopressor support to maintain systemic pressures in cardiac surgery patients. ${ }^{23}$ These results suggest that the ability of this agent to treat perioperative $\mathrm{PH}$ is limited by its systemic effects. However, milrinone has demonstrated effectiveness in promoting selective pulmonary vasodilation in heart transplant candidates with baseline $\mathrm{PH}$ when administered through inhalation. ${ }^{71}$ The decrease in PVR only occurred in patients who exhibited $\mathrm{PH}$ and did not lead to complications in patients with normal hemodynamic values. ${ }^{71}$ When used in combination with inhaled prostacyclin, milrinone potentiated pulmonary vasodilation after cardiac surgery. ${ }^{72}$ Although stroke volume increased and there was prolonged PVR reduction, SVR and MAP were unaffected. ${ }^{72}$ Compared with NO or prostacyclin analogues, milrinone was also able to uniquely reduce pulmonary capillary wedge pressure and may provide an additional means of managing patients with pulmonary venous hypertension and preserved ejection fractions. ${ }^{11}$ Because selective pulmonary vasodilator therapy in such patients may lead to clinical aggravation through increased left ventricular loading, milrinone's unique properties may provide more ideal therapy.

\section{Sildenafil}

By inhibiting type 5 phosphodiesterases, sildenafil maintains cGMP levels, promotes the action of NO, and has been administered in various contexts of $\mathrm{PH}$ management. As oral sildenafil is easy to administer and exhibits pulmonary specificity by reducing PAP without affecting systemic pressure, this agent has also been utilized as monotherapy to treat perioperative PH. Sildenafil has been used to treat PH in both pediatric and adult patients who have undergone cardiac surgery. Hemodynamic monitoring has revealed significant decreases in PAP and PVR without any reported incidence of systemic hypotension, pulmonary hypertensive crisis, or rebound $\mathrm{PH} .{ }^{73-75}$ Sildenafil has also been found to have a potentially protective effect in managing moderate-tosevere PH in congenital heart surgery. Sildenafil administered before and after CPB not only lowers mean PAP, but patients also experienced shorter $\mathrm{CPB}$ and mechanical ventilation times and decreased lengths of intensive care unit admission. ${ }^{75}$

Sildenafil has also been used in combination with other agents to augment their vasodilatory effects or to limit the impact of their withdrawal. In addition to facilitating NO discontinuation, sildenafil has been administered with inhaled NO to treat $\mathrm{PH}$ after valve replacement surgery. This combination produced a greater degree of selective pulmonary vasodilation compared with either agent alone. ${ }^{76} \mathrm{Com}-$ bination therapy with oral sildenafil and inhaled iloprost was more effective than either agent alone in treating severe $\mathrm{PH}$ as well. ${ }^{77}$ Sildenafil has also been used as adjunctive therapy in managing adult cardiac surgery patients who experience persistent PH despite treatment with isoproterenol, milrinone, SNP, nitroglycerin, or NO. Hemodynamic data collected before and after sildenafil administration demonstrated reductions in mean PAP and PVR. ${ }^{78}$ Regular dosing enabled these patients to be successfully weaned from vasodilators without rebound $\mathrm{PH}$, in-hospital mortality, or significant systemic effects on cardiac index, MAP, or SVR. ${ }^{78}$

It is important to note that some studies have suggested that sildenafil may have limited pulmonary specificity and can 
even worsen morbidity and mortality. When infants at risk for $\mathrm{PH}$ were treated with $\mathrm{NO}$ and intravenously administered sildenafil after septal defect closure, PVR reduction was augmented, but patients also experienced hypotension and significant decreases in arterial $\mathrm{O}_{2}$ levels that were not ameliorated with additional NO administration. ${ }^{79}$ Furthermore, the FDA recently issued a warning on the safety of longterm sildenafil use in children with pulmonary arterial hypertension as high doses have been associated with increased rates of mortality. ${ }^{80}$

\section{CONCLUSIONS}

Patients with $\mathrm{PH}$ should undergo thorough preoperative assessment and careful perioperative monitoring to ensure optimal systemic perfusion, RV preload, and RV contractility. At our institution, perioperative $\mathrm{PH}$ is pharmacologically managed through the use of continuously nebulized pulmonary vasodilators, such as prostacyclins. Due to its costs, NO is rarely used. Agents such as sildenafil are used either as prophylactic treatment for suspected or anticipated $\mathrm{PH}$ or as an adjunct to pulmonary vasodilators when combination therapy is considered.

Pulmonary hypertension complicates the operative course of patients undergoing various surgical procedures. However, there is currently a lack of consistent recommendations for perioperative management in the adult population. This can be partially attributed to the multiple pathogenic causes of pulmonary hypertension, which can present within various contexts in either the acute or chronic setting, and the underrecognition of $\mathrm{PH}$ before surgery. Although studies on the variety of available treatment options reveal promising results, specific guidelines are needed to identify which treatments would best benefit specific patient populations.

\section{REFERENCES}

1. Reich DL, Bodian CA, Krol M, et al. Intraoperative hemodynamic predictors of mortality, stroke, and myocardial infarction after coronary artery bypass surgery. Anesth Analg. 1999;89:814-822.

2. Reich DL, Wood RK Jr, Emre S, et al. Association of intraoperative hypotension and pulmonary hypertension with adverse outcomes after orthotopic liver transplantation. J Cardiothorac Vasc Anesth. 2003;17: 699-702.

3. Lai HC, Lai HC, Wang KY, et al. Severe pulmonary hypertension complicates postoperative outcome of non-cardiac surgery. $\mathrm{Br} J$ Anaesth. 2007;99:184-190.

4. Ramakrishna G, Sprung J, Ravi BS, et al. Impact of pulmonary hypertension on the outcomes of noncardiac surgery: predictors of perioperative morbidity and mortality. J Am Coll Cardiol. 2005;45:1691-1699.

5. Corciova FC, Corciova C, Georgescu CA, et al. Echocardiographic predictors of adverse short-term outcomes after heart surgery in patients with mitral regurgitation and pulmonary hypertension. Heart Surg Forum. 2012;15:E127-E132.

6. Chen JM, Levin HR, Michler RE, et al. Reevaluating the significance of pulmonary hypertension before cardiac transplantation: determination of optimal thresholds and quantification of the effect of reversibility on perioperative mortality. J Thorac Cardiovasc Surg. 1997;114:627-634.

7. Krowka MJ, Plevak DJ, Findlay JY, et al. Pulmonary hemodynamics and perioperative cardiopulmonary-related mortality in patients with portopulmonary hypertension undergoing liver transplantation. Liver Transpl. 2000;6:443-450
8. Brown LM, Chen H, Halpern S, et al. Delay in recognition of pulmonary arterial hypertension: factors identified from the REVEAL Registry. Chest. 2011;140:19-26.

9. Simonneau G, Robbins IM, Beghetti M, et al. Updated clinical classification of pulmonary hypertension. J Am Coll Cardiol. 2009;54:S43-S54.

10. Jacobs AK, Leopold JA, Bates E, et al. Cardiogenic shock caused by right ventricular infarction. $J$ Am Coll Cardiol. 2003;41:1273-1279.

11. Hultgren $\mathrm{HN}$, Miyagawa $\mathrm{M}$, Buch $\mathrm{W}$, et al. Ischemic myocardial injury during cardiopulmonary bypass surgery. Am Heart J. 1973; $85: 167-176$

12. Chai PJ, Williamson JA, Lodge AJ, et al. Effects of ischemia on pulmonary dysfunction after cardiopulmonary bypass. Ann Thorac Surg. 1999; 67:731-735.

13. Fullerton DA, McIntyre RC, Kirson LE, et al. Impact of respiratory acidbase status in patients with pulmonary hypertension. Ann Thorac Surg. 1996;61:696-701.

14. Chang AC, Zucker HA, Hickey PR, et al. Pulmonary vascular resistance in infants after cardiac surgery: role of carbon dioxide and hydrogen ion. Crit Care Med. 1995;23:568-574.

15. Morray JP, Lynn AM, Mansfield PB. Effect of $\mathrm{pH}$ and $\mathrm{PCO} 2$ on pulmonary and systemic hemodynamics after surgery in children with congenital heart disease and pulmonary hypertension. J Pediatr. 1988;113: 474-479.

16. Bogaard HJ, Abe K, Vonk Noordegraaf A, et al. The right ventricle under pressure: cellular and molecular mechanisms of right-heart failure in pulmonary hypertension. Chest. 2009;135:794-804.

17. Morris K, Beghetti M, Petros A, et al. Comparison of hyperventilation and inhaled nitric oxide for pulmonary hypertension after repair of congenital heart disease. Crit Care Med. 2000;28:2974-2978.

18. Russell IA, Zwass MS, Fineman JR, et al. The effects of inhaled nitric oxide on postoperative pulmonary hypertension in infants and children undergoing surgical repair of congenital heart disease. Anesth Analg. 1998;87:46-51

19. Miller OI, Tang SF, Keech A, et al. Inhaled nitric oxide and prevention of pulmonary hypertension after congenital heart surgery: a randomised double-blind study. Lancet. 2000;356:1464-1469.

20. Beck JR, Mongero LB, Kroslowitz RM, et al. Inhaled nitric oxide improves hemodynamics in patients with acute pulmonary hypertension after high-risk cardiac surgery. Perfusion. 1999;14:37-42.

21. Fattouch K, Sbraga F, Bianco G, et al. Inhaled prostacyclin, nitric oxide, and nitroprusside in pulmonary hypertension after mitral valve replacement. J Card Surg. 2005;20:171-176.

22. Fernandes JL, Sampaio RO, Brandao CM, et al. Comparison of inhaled nitric oxide versus oxygen on hemodynamics in patients with mitral stenosis and severe pulmonary hypertension after mitral valve surgery. Am J Cardiol. 2011;107:1040-1045.

23. Solina A, Papp D, Ginsberg S, et al. A comparison of inhaled nitric oxide and milrinone for the treatment of pulmonary hypertension in adult cardiac surgery patients. J Cardiothorac Vasc Anesth. 2000;14: $12-17$.

24. Day RW, Hawkins JA, McGough EC, et al. Randomized controlled study of inhaled nitric oxide after operation for congenital heart disease. Ann Thorac Surg. 2000;69:1907-1912; Discussion 1913.

25. Weinberger B, Laskin DL, Heck DE, et al. The toxicology of inhaled nitric oxide. Toxicol Sci. 2001;59:5-16.

26. Gow AJ, Thom SR, Ischiropoulos $\mathrm{H}$. Nitric oxide and peroxynitritemediated pulmonary cell death. Am J Physiol. 1998;274:L112-L118.

27. Matalon S, DeMarco V, Haddad IY, et al. Inhaled nitric oxide injures the pulmonary surfactant system of lambs in vivo. Am J Physiol. 1996;270: L273-L280.

28. Evans T, Carpenter A, Kinderman H, et al. Evidence of increased nitric oxide production in patients with the sepsis syndrome. Circ Shock. 1993; 41:77-81

29. Ochoa JB, Udekwu AO, Billiar TR, et al. Nitrogen oxide levels in patients after trauma and during sepsis. Ann Surg. 1991;214:621-626.

30. Shi Y, Li HQ, Shen CK, et al. Plasma nitric oxide levels in newborn infants with sepsis. J Pediatr. 1993;123:435-438.

31. Lavoie A, Hall JB, Olson DM, et al. Life-threatening effects of discontinuing inhaled nitric oxide in severe respiratory failure. Am J Respir Crit Care Med. 1996;153:1985-1987.

32. Atz AM, Adatia I, Wessel DL. Rebound pulmonary hypertension after inhalation of nitric oxide. Ann Thorac Surg. 1996;62:1759-1764. 
33. Black SM, Heidersbach RS, McMullan DM, et al. Inhaled nitric oxide inhibits NOS activity in lambs: potential mechanism for rebound pulmonary hypertension. Am J Physiol. 1999;277: H1849-H1856.

34. Thelitz S, Bekker JM, Ovadia B, et al. Inhaled nitric oxide decreases pulmonary soluble guanylate cyclase protein levels in 1-month-old lambs. J Thorac Cardiovasc Surg. 2004;127:1285-1292.

35. Pearl JM, Nelson DP, Raake JL, et al. Inhaled nitric oxide increases endothelin-1 levels: a potential cause of rebound pulmonary hypertension. Crit Care Med. 2002;30:89-93.

36. Kageyama K, Shime N, Hirose M, et al. Factors contributing to successful discontinuation from inhaled nitric oxide therapy in pediatric patients after congenital cardiac surgery. Pediatr Crit Care Med. 2004; 5:351-355.

37. Namachivayam $P$, Theilen $U$, Butt WW, et al. Sildenafil prevents rebound pulmonary hypertension after withdrawal of nitric oxide in children. Am J Respir Crit Care Med. 2006;174:1042-1047.

38. Lee JE, Hillier SC, Knoderer CA. Use of sildenafil to facilitate weaning from inhaled nitric oxide in children with pulmonary hypertension following surgery for congenital heart disease. J Intensive Care Med. 2008; 23:329-334.

39. Schutte H, Grimminger F, Otterbein J, et al. Efficiency of aerosolized nitric oxide donor drugs to achieve sustained pulmonary vasodilation. J Pharmacol Exp Ther. 1997;282:985-994.

40. Yu XQ, Saugstad OD. Nebulization of sodium nitroprusside in lunglavaged newborn piglets. Pediatr Res. 1999;45:255-259.

41. Meadow W, Rudinsky B, Bell A, et al. Effects of nebulized nitroprusside on pulmonary and systemic hemodynamics during pulmonary hypertension in piglets. Pediatr Res. 1998;44:181-186.

42. Adrie C, Ichinose F, Holzmann A, et al. Pulmonary vasodilation by nitric oxide gas and prodrug aerosols in acute pulmonary hypertension. $J$ Appl Physiol. 1998;84:435-441.

43. Bando M, Ishii Y, Kitamura S, et al. Effects of inhalation of nitroglycerin on hypoxic pulmonary vasoconstriction. Respiration. 1998; 65:63-70.

44. Mandal B, Kapoor PM, Chowdhury U, et al. Acute hemodynamic effects of inhaled nitroglycerine, intravenous nitroglycerine, and their combination with intravenous dobutamine in patients with secondary pulmonary hypertension. Ann Card Anaesth. 2010;13: $138-144$

45. Goyal P, Kiran U, Chauhan S, et al. Efficacy of nitroglycerin inhalation in reducing pulmonary arterial hypertension in children with congenital heart disease. Br J Anaesth. 2006;97:208-214.

46. Omar HA, Gong F, Sun MY, et al. Nebulized nitroglycerin in children with pulmonary hypertension secondary to congenital heart disease. $W V$ Med J. 1999;95:74-75.

47. Yurtseven N, Karaca P, Kaplan M, et al. Effect of nitroglycerin inhalation on patients with pulmonary hypertension undergoing mitral valve replacement surgery. Anesthesiology. 2003;99:855-858.

48. Yurtseven N, Karaca P, Uysal G, et al. A comparison of the acute hemodynamic effects of inhaled nitroglycerin and iloprost in patients with pulmonary hypertension undergoing mitral valve surgery. Ann Thorac Cardiovasc Surg. 2006;12:319-323.

49. Rajek A, Pernerstorfer T, Kastner J, et al. Inhaled nitric oxide reduces pulmonary vascular resistance more than prostaglandin $\mathrm{E}(1)$ during heart transplantation. Anesth Analg. 2000;90:523-530.

50. Schroeder RA, Wood GL, Plotkin JS, et al. Intraoperative use of inhaled PGI(2) for acute pulmonary hypertension and right ventricular failure. Anesth Analg. 2000;91:291-295.

51. Haraldsson A, Kieler-Jensen N, Ricksten SE. Inhaled prostacyclin for treatment of pulmonary hypertension after cardiac surgery or heart transplantation: a pharmacodynamic study. J Cardiothorac Vasc Anesth. $1996 ; 10: 864-868$

52. De Wet CJ, Affleck DG, Jacobsohn E, et al. Inhaled prostacyclin is safe, effective, and affordable in patients with pulmonary hypertension, right heart dysfunction, and refractory hypoxemia after cardiothoracic surgery. J Thorac Cardiovasc Surg. 2004;127: $1058-1067$

53. Hache M, Denault AY, Belisle S, et al. Inhaled epoprostenol (prostacyclin) and pulmonary hypertension before cardiac surgery. $J$ Thorac Cardiovasc Surg. 2003;125:642-649.
54. Schroeder RA, Rafii AA, Plotkin JS, et al. Use of aerosolized inhaled epoprostenol in the treatment of portopulmonary hypertension. Transplantation. 2000;70:548-550.

55. Hache M, Denault AY, Belisle S, et al. Inhaled prostacyclin (PGI2) is an effective addition to the treatment of pulmonary hypertension and hypoxia in the operating room and intensive care unit. Can J Anaesth. 2001; 48:924-929.

56. Khan TA, Schnickel G, Ross D, et al. A prospective, randomized, crossover pilot study of inhaled nitric oxide versus inhaled prostacyclin in heart transplant and lung transplant recipients. $J$ Thorac Cardiovasc Surg. 2009;138:1417-1424.

57. Mikhail G, Gibbs J, Richardson M, et al. An evaluation of nebulized prostacyclin in patients with primary and secondary pulmonary hypertension. Eur Heart J. 1997; 18:1499-1504.

58. Haraldsson A, Kieler-Jensen N, Wadenvik H, et al. Inhaled prostacyclin and platelet function after cardiac surgery and cardiopulmonary bypass. Intensive Care Med. 2000;26:188-194.

59. Augoustides JG, Culp K, Smith S. Rebound pulmonary hypertension and cardiogenic shock after withdrawal of inhaled prostacyclin. Anesthesiology. 2004;100:1023-1025.

60. Rex S, Schaelte G, Metzelder S, et al. Inhaled iloprost to control pulmonary artery hypertension in patients undergoing mitral valve surgery: a prospective, randomized-controlled trial. Acta Anaesthesiol Scand. 2008;52:65-72

61. Theodoraki K, Rellia P, Thanopoulos A, et al. Inhaled iloprost controls pulmonary hypertension after cardiopulmonary bypass. Can J Anaesth. 2002;49:963-967.

62. Langer F, Wendler O, Wilhelm W, et al. Treatment of a case of acute right heart failure by inhalation of iloprost, a long-acting prostacyclin analogue. Eur J Anaesthesiol. 2001;18:770-773.

63. Kramm T, Eberle B, Guth S, et al. Inhaled iloprost to control residual pulmonary hypertension following pulmonary endarterectomy. Eur $J$ Cardiothorac Surg. 2005;28:882-888.

64. Limsuwan A, Wanitkul S, Khosithset A, et al. Aerosolized iloprost for postoperative pulmonary hypertensive crisis in children with congenital heart disease. Int J Cardiol. 2008:129:333-338.

65. Langer F, Wilhelm W, Tscholl D, et al. Intraoperative inhalation of the long-acting prostacyclin analog iloprost for pulmonary hypertension. $J$ Thorac Cardiovasc Surg. 2003;126:874-875.

66. Hoeper MM, Olschewski H, Ghofrani HA, et al. A comparison of the acute hemodynamic effects of inhaled nitric oxide and aerosolized iloprost in primary pulmonary hypertension. $J$ Am Coll Cardiol. 2000;35: 176-182.

67. Loukanov T, Bucsenez D, Springer W, et al. Comparison of inhaled nitric oxide with aerosolized iloprost for treatment of pulmonary hypertension in children after cardiopulmonary bypass surgery. Clin Res Cardiol. 2011;100:595-602.

68. Winterhalter M, Simon A, Fischer S, et al. Comparison of inhaled iloprost and nitric oxide in patients with pulmonary hypertension during weaning from cardiopulmonary bypass in cardiac surgery: a prospective randomized trial. J Cardiothorac Vasc Anesth. 2008:22:406-413.

69. Sablotzki A, Hentschel T, Gruenig E, et al. Hemodynamic effects of inhaled aerosolized iloprost and inhaled nitric oxide in heart transplant candidates with elevated pulmonary vascular resistance. Eur J Cardiothorac Surg. 2002;22:746-752.

70. Kawashima M, Nakamura T, Schneider S, et al. Iloprost ameliorates postischemic lung reperfusion injury and maintains an appropriate pulmonary ET-1 balance. J Heart Lung Transpl. 2003;22:794-801.

71. Sablotzki A, Starzmann W, Scheubel R, et al. Selective pulmonary vasodilation with inhaled aerosolized milrinone in heart transplant candidates. Can J Anaesth. 2005;52:1076-1082.

72. Haraldsson SA, Kieler-Jensen N, Ricksten SE. The additive pulmonary vasodilatory effects of inhaled prostacyclin and inhaled milrinone in postcardiac surgical patients with pulmonary hypertension. Anesth Analg. 2001;93:1439-1445, Table of contents.

73. Peiravian F, Amirghofran AA, Borzouee M, et al. Oral sildenafil to control pulmonary hypertension after congenital heart surgery. Asian Cardiovasc Thorac Ann. 2007;15:113-117.

74. Shim JK, Choi YS, Oh YJ, et al. Effect of oral sildenafil citrate on intraoperative hemodynamics in patients with pulmonary hypertension undergoing valvular heart surgery. J Thorac Cardiovasc Surg. 2006;132: $1420-1425$. 
75. Palma G, Giordano R, Russolillo V, et al. Sildenafil therapy for pulmonary hypertension before and after pediatric congenital heart surgery. Tex Heart Inst J. 2011;38:238-242.

76. Matamis D, Pampori S, Papathanasiou A, et al. Inhaled NO and sildenafil combination in cardiac surgery patients with out-of-proportion pulmonary hypertension: acute effects on postoperative gas exchange and hemodynamics. Circ Heart Fail. 2012;5:47-53.

77. Ghofrani HA, Wiedemann R, Rose F, et al. Combination therapy with oral sildenafil and inhaled iloprost for severe pulmonary hypertension. Ann Intern Med. 2002;136:515-522.
78. Trachte AL, Lobato EB, Urdaneta F, et al. Oral sildenafil reduces pulmonary hypertension after cardiac surgery. Ann Thorac Surg. 2005;79: 194-197; Discussion 194-197.

79. Stocker C, Penny DJ, Brizard CP, et al. Intravenous sildenafil and inhaled nitric oxide: a randomised trial in infants after cardiac surgery. Intensive Care Med. 2003;29:1996-2003.

80. Barst RJ, Ivy DD, Gaitan G, et al. A randomized, double-blind, placebocontrolled, dose-ranging study of oral sildenafil citrate in treatment-naive children with pulmonary arterial hypertension. Circulation. 2012;125: 324-334. 